\title{
Performance Enhancement of Low Voltage Distribution Network in Developing Countries using Hybrid Rehabilitation Technique
}

\author{
HASHAM KHAN*, AND MOHAMMAD AHMED CHOUDHRY* \\ RECEIVED ON 06.03.2017 ACCEPTED ON 29.05.2017
}

\begin{abstract}
Majority of the developing countries are facing problem of low supply voltage coupled with shortage of electrical energy. There is a growing concern for ways and means to preserve the existing resources and optimize the performance of EPDS (Electric Power Distribution System). Poor condition of distribution network, utilization of low current carrying capacity conductors with overloading is mainly causing the voltage drop, power loss and energy loss in the LVDN (Low Voltage Distribution Networks). Most of developing countriesare encountered with financial problems to ward up gradation of the existing network. Under such circumstances, it is essential to optimize the low voltage distribution network using innovative approach to design the LVDN.

In thiswork, ahybrid rehabilitation techniqueis used for the performance improvement of LVD utilities network. Most of the availablealgorithms areconsidering the distribution networks with balance distributed load andunity power factor. The proposed methodology has been applied to LVDN, working under randomly distributed load with low power factor. The technique is applied to improve the efficiency of LVDN in terms of power loss and voltage drop reduction. Optimization of three different circuits of village QutabFerozal, Banth and Pothi Mandra of IESCO, has been selected as a case study. The analysis has been performed using ELR (Energy Loss Reduction) and CADPAD (Computer Aided Distribution Planning and Design) software. Field visits have been conducted to acquire the real data of various LVDN configurations. Simulation results are validated with the actual data of the selected LVDN feeders and found within the permissible limits.
\end{abstract}

Key Words: Energy Loss Reduction, Computer Aided Distribution Planning and Design, Electric Power Distribution System, Optimization of Low Voltage Distribution Networks, Radial Distribution Feeder.

\section{INTRODUCTION}

7 provide the electric utility service of required quality at the optimum cost, permissible voltage drop with minimum power and energy loss is vital. EPDS is a linkage between transmission system and
LVDN. In LVD system, $I^{2} R$ losses are mostlydue to low voltage and high current. These losses represent the largest consumption in electrical power system [1]. Different techniques of power loss reduction exist in the 
literature. Some of them are feeder reconfiguration, placement of capacitor, grading of conductor, high voltage distribution system and optimal placement of distributed generator. Mostly, feeder reconfiguration is applied for eliminating line resistive losses in the distribution system [2]. The optimal application of capacitor in LVDN significantly reduces the voltage drop, minimize the power loss, release feeder capacity, increase power factor and compensate reactive power [3]. The implementation of ALT (Automatic Load Transfer) switch may provide some potential benefits including voltage regulation, maximum utilization of available assets and power loss reduction. However, the application of ALT switch depends upon the network reconfiguration and load connected [4]. Power loss is more than $10 \%$ in developed countries, whereas, it is more than $20 \%$ in developing countries. However, ideally power loss in any distribution system must not exceed $6 \%$ [5].

Majority of the distribution networks are assumed to be complicated because of frequent power outages. The end customers always encountered the problems of voltage drop and power loss [6]. An evolutionary algorithm, called as DFR (Distribution Feeder Reconfiguration) has been proposed in [7]. The algorithm minimizes the power loss and the operating cost of distributed generation. However, it will be effective, only when the network is of radial nature and the transformer capacity, bus voltage and the network thermal limits are within the acceptable limit. Optimization techniques used for optimum size and location of capacitor placement in the distribution network can be divided into different categories. Few of them are; AI (Artificial Intelligent), conventional and hybrid intelligent techniques [8]. In the conventional techniques sufficient time is needed for convergence. Majority of the $\mathrm{AI}$ and hybrid intelligent optimization methods are complicated and uneconomical to implement practically. The aggregate technical and commercial losses are estimated to be $25-30 \%$ [9]. The electric utilities are trying to bring these losses below $15 \%$, using various innovative techniques.In order toimprove the power quality and the efficiency of the LVDN, priority should be given to the up-gradation, customer orientation, decentralization of embedded generation and theft control in the distribution system.In general, load is inductive, hence with the increase of inductive load, the power factor of the LVDN decreases. Reduced power factor increases the distribution system complexities in terms of reduced system capacity, voltage regulation, power factor penalties, and increased voltage drop and energy losses, especially at the customer terminals [10].

Many electric utilities are facing the problem of voltage drop and energy loss. The distribution networks of developing countrieslike Pakistan are long, deteriorated and overloaded with unbalanced loads. The maximum allowed voltage variation is $\pm 5 \%$ as stated in the IEEE standards. The power loss and voltage drop adversely affects the efficiency of the LVDN. To improve the efficiency of LVDN, a strategic planning is required. The voltage drop and power loss mostly varies with the pattern of loading on the distribution feeder [10]. Different techniques are used to minimize the issues related to power loss and voltage drop. Majority of the EPDNs are radial in configuration. The developing countries of the world are facing the obstacles in mitigating and avoiding the non-technical losses.

The implementation of AMI (Advance Metering Infrastructure) technique with smart meters, control these losses up to some extent [11]. Increasing the power factor of LVDN can significantly minimize the lossesalong with average loading of the LVDN. In many cases, excessive distribution loss occurs on account of illegal connection and non-technical losses (pilferage). Under such circumstances, unpaid energy bills are responsible for creating liquid cash crunch and reduce the revenue collection efficiency. A reasonable investment and 
application of managerial measures are needed to minimize such distribution losses [12]. Shifting of distribution transformers to their optimal locations and the installation of capacitor banksin the LVDN will not only improve the voltage profile but also enhance the useful life of EPDS equipment [13].

Loss reduction and increased system capacity may be achieved by efficiently altering the condition of sectionalizing switches [14]. However, such method of reconfiguration is effective only for radial distribution networks. In Pakistan, primary distribution voltage level is $11 \mathrm{kV}$. Near the customer terminal $11 \mathrm{kV}$ is stepped-down through step-down transformer to low voltage level (400V, three phase and four wires). The voltage between any phase and neutral is 230 Vand between two phases is $400 \mathrm{~V}$. Single phase is used for light-load whereas; three phases are used for heavy-load forresidential and commercial consumers. Usually low voltage distribution is carried out through three phase four wires, two phase three wires and single phase two wires system. The existing distribution system in Pakistan consists of large three phase $11 \mathrm{kV}$ distribution feeders with three phase lines. Mostly in LVDN, voltage drop occurs due to the utilization of low current carrying capacity conductors and long length. The loss of energy in the LVDN exists due to commercial and technical losses. Technical losses include energy dissipation in the line conductors and equipment involved in distribution of electric power. The commercial losses are mainly because of pilferage and error in the measuring equipment. These losses depend upon the load density, configuration of LVDN and the energy pattern used.

To keep the voltage of LVDN within acceptable range and to eliminate power loss, numerous techniques including distributed generation at strategic location, application of electrical storage devices as well asproperly designed and operated embedded generation can be used effectively [15]. Using proper size of standard conductor with appropriate parameters minimizes theelectrical power consumption; enhances the voltage regulation, reduces the power loss and improvesthe performanceof electrical equipment [16]. It has been observed that majority of transformers are without energy meters and average consumption is estimated which lead to an error in the estimation of energy. In most of the LVDN, the voltage variations are more than $10 \%$. Inductive loads, especially induction motors draw higher current at reduced voltage for the constant output, causing significant voltage reduction in the LVDN. The full load current drawn by the induction motor is $15 \%$ when the voltage drop of LVDN is $10 \%$. Similarly for the same voltage drop, the line loss increases to $20 \%$ and the starting torque decreases by $19 \%$ in the LVDN [16].

Because of rapid increase in population, the LVDNs are growing larger and stretched too farresulting in deteriorated system voltage regulation [17]. Detailed analyses delineate that maximum losses are owing to the LVDN part of the power system. As per one estimate it accounts for $80-90 \%$ of the total transmission and distribution losses [18]. The initiative for improving the LVDN includes system up-gradation, preventive maintenance, rectification of defective switch gears as well as loose termination at substations and checking proper operation of capacitors banks. To balancethe load, single phase three wire lines are replaced by three phase five wires lines. To increase voltage regulation another low tension circuit is constructed for low voltage lines having current larger than $75 \mathrm{~A}$ and length more than 5 $\mathrm{kM}$.

The acceptable regulation limit for LVD circuit is 6\% and for high voltage distribution network is $8 \%$. Over-loaded transformer extracts needless high iron losses. Low power factorin low voltagelines, also contributes high distribution losses [18-19]. In distribution circuit having

Mehran University Research Journal of Engineering \& Technology, Volume 37, No. 3, July, 2018 [p-ISSN: 0254-7821, e-ISSN: 2413-7219] 
low power factor, the current drawn is maximum consequently the loss is proportional to the current. The reduction of losses in LVDN can be considered as source of energy. The reconfiguration of LVDN can play a significant role in reducing the line losses and improving the voltage profile. This in turn notonly reduces the system operating cost but also minimizes the temperature of the line components, as a result the "phenomena of aging" in the system insulation and failure rate of components are reduced [20]. A fast restoration strategy based on the feeder dispatch control system for feeder reconfiguration has been proposed by Lin and Chin [21]. The method is capable of minimizing losses in the distribution network. However, the proposed method is complicated as a lot ofcomputational work is required which may affect the end results adversely. Power loss in EPDS increases the temperature of various electrical components leading to insulation failure [22]. Configuration management is used to reduce the distribution network losses. However, it is a discrete optimization problem for which the radial structure of the feeder is required [23].

In this research work, three low tension distribution networks of Mandara Feeder, Rawalpindi Sub-Division and IESCO, Islamabad, Pakistan has been taken as a case study. The analyses have been carried out using hybrid rehabilitation technique. Different rehabilitation techniques have been studied and emphases have been given to upgrade the existing outdated LVDN using hybrid rehabilitation technique. The results are verified and are within the permissible limits.

\section{MAIN CAUSES OF VOLTAGE DROP AND POWER LOSS}

Mostly LVDN comprises of inductive loads. Reactive power is essentially needed to magnetize the Inductive loads. It has been observed that heat loss in LVDN conductors causes significant voltage drop. Most of the developing countries are deficient in financial resources and populated with heavily overloaded distribution network and undersized conductors. Unfortunately, there is no proper method used in these countries for accurate field data collection. Most of the data collected is based on the information provided by the customer's application forms which is mostlyless than the actual demand. Due to lackof latest design and simulation facilities, there are significant chances of error in load forecasting and data collection of LVDN. On the bases of in accurate information, the LVDN becomes overloaded resulting in excessive power loss and voltage drop in the electric power distribution network.

It has been observed that during the data collection in the field survey, mostof the LVDN transformers on load ranging from $40-50 \%$ have maximum efficiency. In majority of Utility Companies, the LVDN transformers along with secondary circuitsare responsible for prominent power loss and voltage drop.In the distribution company of Pakistan WAPDA (Water and Power Development Authority), approximately $60 \%$ of distribution transformers are unbalanced. Unbalanced load on distribution transformer enhances the heat losses from 5-6\%. LVDN loads are mostly designed as constant current. The power loss equation for LVDN can be written as:

$\Delta P_{T F}=\sum_{i=1}^{N} R_{i} I_{i}^{2}$

The overall power losses are:

$\Delta P=\Delta P_{T F}+\sum_{j=1}^{N_{b}} R_{j} I_{j}^{2}$

Where $R_{i}$ is Resistance of the $i^{\text {th }}$ transformer, $R_{j}$ is Resistance of $\mathrm{j}^{\text {th }}$ branch, $\mathrm{N}$ is Substation where 
transformers of $\mathrm{A}_{\mathrm{i}}$ rated power are installed, $\mathrm{N}_{\mathrm{b}}$ is Branches of distribution network, and $\mathrm{I}_{\mathrm{i}}, \mathrm{I}_{\mathrm{j}}$ are the relevant currents.

The service cables are of shorter length, hence have minimum effect on voltage drop and power loss of LVDN. During the field survey of the rural areas it has been noticed that the majority of the domestic customers load are connected through a single service cable. Under such circumstances the quality of electric supply is affected badly. Error in the data collection, nature of LVDN load, equipment design, layout of the installation, weak maintenance of LVDN and low power factor are the key factors of power loss and voltage drop in LVDN.

Nominal voltage ratings in pu (per unit) system:

$\mathrm{V}(\mathrm{nom})=1.00 \mathrm{pu}$

$\mathrm{V}(\max )=1.05 \mathrm{pu}$

$\mathrm{V}(\min )=0.95 \mathrm{pu}$

Where $\mathrm{V}($ nom $)$ is the nominal voltage $\mathrm{pu}, \mathrm{V}(\max )$ is the maximum voltage $\mathrm{pu}$, and $\mathrm{V}(\mathrm{min})$ is the minimum voltage pu.

Considering simply the magnitude of voltage, the VPI (Voltage Profile Improvement) for $\mathrm{i}^{\text {th }}$ node may be depicted as:

$V P_{i}=\frac{\left(V_{i}-V \min \right)\left(V \max -V_{i}\right)}{(V n o n-V \min )(V \max -V \text { nom })}$

Where $\mathrm{V}_{\mathrm{i}}$ is the pu voltage at $\mathrm{i}^{\text {th }}$ node.

Resultant voltage profile index is

$\mathrm{VP}_{\mathrm{i}}=\frac{1}{\mathrm{~N}} \sum_{\mathrm{i}=1}^{\mathrm{n}} \mathrm{VPi}$

Where $\mathrm{N}$ is the number of the nodes.
To obtain more precise results, a weighting factor is introduced based on the importance of different loads. For equally weighted node weighting factor is taken as 1 . Under such circumstances Equation (3) can be re-written as:

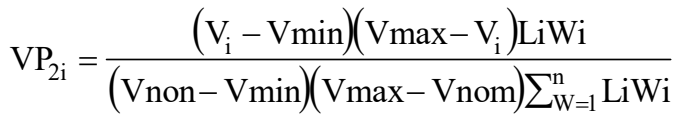

Where $\mathrm{VP}_{2 \mathrm{i}}$ is the per unit voltage at $\mathrm{i}^{\text {th }}$ node with "weighting factor", $\left(\mathrm{W}_{\mathrm{i}}\right), \mathrm{L}_{\mathrm{i}}$ is the load providedat ith node.

The voltage profile index illustrated in Equation (5) maybe expressedas:

$\mathrm{VP}_{2}=\sum_{\mathrm{i}=1}^{\mathrm{n}} \mathrm{V}_{\mathrm{i}} \mathrm{L}_{\mathrm{i}} \mathrm{W}_{\mathrm{i}}$

The general expression for voltage profile of the EPDS can be rewritten as:

$\mathrm{VP}=\sum_{\mathrm{i}=1}^{\mathrm{n}} \mathrm{V}_{\mathrm{i}} \mathrm{L}_{\mathrm{i}} \mathrm{W}_{\mathrm{i}}$

Where VP is the voltage profile, $\mathrm{V}_{\mathrm{i}}$ is the voltage of ithnode in $\mathrm{pu}, \mathrm{L}_{\mathrm{i}}$ is the load supplied at ith node, $\mathrm{n}$ the number of the node, and $\mathrm{W}_{\mathrm{i}}$ is the weighting factor of the ith node.

Practically, it has been observed that the common expression used for voltage profile is applicable when voltages of all the nodes are within the acceptable range of $\pm 5 \%$ of the normal voltage rating [24]. Per unit"voltage profile index" is 0 at 0.95 and 1.05 . It has the highest value 1.0 when voltages of all the nodes are at their usualnormal values. However, in case of any voltage decrease or increase exceeding the normal value, the "voltage profile" of the LVDN changes drastically, showing the precise picture of the LVDN.

In the competitive environment, the distribution companies are passing through the era of deregulation 
and with the advent of sophisticated telecommunication facilities, the consumers are aware of the power quality issues. Reduction of power loss improves the tension profile in the nodes, enhances the safety and reliability of the distribution network and ensures the uninterruptible power supply. Mostly, it is observed that by enhancing the voltage profile of LVDN, the active power and reactive power losses are minimized and the overall performance of the LVDN is increased. Power factor and voltage along the distribution network also changes during the peak hours. Under such situation, it is necessary to increase the efficiency of LVDN by minimizing the power lossand voltage drop effectively. The LVDN is checked against as a minimum requirement in predetermined planning criteria. It ensures specified standard guidelines for LVDN.

Haphazard planning of distribution network causes lengthy LVDN instead of shortest path to a locality, which increases the voltage drop and power loss in EPDS. The transformers location has considerable effect on the voltage drop. Non-optimal location of distribution transformer may also increase the power loss and voltage drop in the LVDN.Mostly, the dimension of conductor used for line connectors between secondary distribution circuit, the transformers terminals and the secondary distribution circuit is much lower than the standard capacity. Also, the conductor used between tee-off lines and main distribution line is of smaller size than the distribution line conductor itself. The application of substandard jointing practices is another key factor of increased voltage drop and power loss in LVDN. In many of cases, loose joints and connectors of smaller size also causes the large amount of hidden power losses and voltage drop in LVDN. Current leakage in an EPDS not only causes the service interruption but also enhances the voltage drop and power loss in LVDN. Violation of standard clearance between distribution line conductors and earth contributes to power loss and voltage drop. Practically it is observed that the loss estimation is mostly inaccurate. In developing countries only $30 \%$ of the total energy consumed is metered [25]. Loads in rural areas are rarely metered and metering is generally limited to thickly populate urban areas. The non-availability of comprehensive data is the main obstacle for computing the losses in distribution system. Under such circumstances, the electric utilities need to evolve loss estimation mechanism which should be reliable enough to convince the regulatory commission [25].

\section{HYBRID REHABILITATION TECHNIQUE}

In the competitive environment, the distribution companies are encountered with the pressure of deregulation in the electric industry. The fast communication media has created power quality awareness among the customers. Under such circumstances, it has become necessary for distribution companies to optimize their LVDN so that the voltage drop and power loss must be minimum as much as possible. During the design of EPDS some assumptions like uniform conductor size, constant loads, equal spacing, uniform load distribution and unity power factor are adopted to make the model more acceptable. However, in actual life scenario, such assumptions are difficult to adopt. Keeping in view of these facts, cumbersome job is needed by distribution engineers in the real world of EPDS. Many issues including the technical, operational, economic, social and environmental are faced during the application of hybrid rehabilitation technique. On the other hand, the implementation of hybrid technique provides remarkable assistance to avoid:

- $\quad$ Excessive voltage drop.

- $\quad$ Huge power loss.

- $\quad$ Unscheduled load shedding.

- $\quad$ Frequent failure in protective system

- $\quad$ Financial loss to customers as well as to electric utilities. 
In such scenario, hybrid rehabilitation technique provides considerable relief to EPDS in a very economical way. While executing the hybrid technique, the calculation of segment data is of immense importance. The input information directly affects the precision and accuracy of the simulation results. LVDN is bifurcated into small sections called segments. The analysis of the distribution system provides the voltage drop and power loss for different nodes and segments of LVDN.

The incremental power loss for " $\mathrm{n}$ " segment is:

$\Delta \mathrm{P}_{\text {loss }}=\int_{\mathrm{x}=\mathrm{n}}^{\mathrm{n}+1} \frac{\mathrm{dI}^{2}}{\mathrm{dt}} \theta_{\mathrm{n}+1} \mathrm{R}_{\mathrm{n}, \mathrm{n}+1} \mathrm{~d}_{\mathrm{x}}$

The total power loss for " $n$ " segment is:

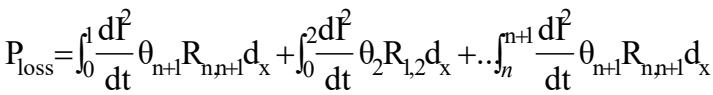

$\mathrm{P}_{\text {loss }}=\sum_{\mathrm{i}=0}^{\mathrm{n}} \frac{\mathrm{dI}^{2}}{\mathrm{dt}} \theta_{\mathrm{i}+1} \mathrm{R}_{\mathrm{i}, \mathrm{i}+1}$

Where $\mathrm{I}=0,1,2, \ldots \mathrm{n}$ Indicate the number of the feeder segment.

" $n$ " segment incremental voltage drop for is:

$\mathrm{dV}_{\mathrm{x}}=\int_{\mathrm{xs}=\mathrm{n}}^{\mathrm{n}+1} \frac{\mathrm{dI}}{\mathrm{dt}} \theta_{\mathrm{n}+1} Z_{\mathrm{n}, \mathrm{n}+1} \mathrm{~d}_{\mathrm{x}}$

At distance " $x$ ", the voltage drop from sending end of the feeder is:

$\mathrm{V}_{\text {drop }}(\mathrm{x})=\mathrm{V}_{\mathrm{s}}-\mathrm{V}_{\mathrm{x}}$

The voltage drop in the respective segment is:

$$
\mathrm{V}_{\mathrm{drop}, \mathrm{n}+1}=\frac{\mathrm{dI}}{\mathrm{dt}} \theta_{\mathrm{n}+1} \mathrm{Z}_{\mathrm{n}, \mathrm{n}+1}
$$

Total voltage drop is:

$$
\mathrm{V}_{\text {drop }}=\mathrm{V}_{\mathrm{s}}-\mathrm{V}_{\mathrm{r}}
$$

The input data can be provided either by the user or through file depending upon the requirements of the user. The data include; number of nodes, rated voltage of the circuit, the type of circuit, length of segment and load connected to each node. The software used for hybrid technique has the capability to calculate the voltage drop, segment current, power loss, node voltage and energy loss. IEEE standards allow only the $\pm 5 \%$ variation in the magnitude of rated value at all the nodes of distribution network [24]. The proposed technique is applied in the following five stages.

In first stage, the input data on prescribed format is provided either through user or file. The technique applied is capable of calculating all segment parameters automatically based upon the input information.

In second stage, the analysis is carried out to investigate whether the power loss and node voltage are within the allowable range. If the results are within the specified range, the consumer has the choice to keep the output within the file which used to generate the power loss curves, voltage profile and other analyses.

In third stage, it executes if power loss and voltage drop of all nodes are out of range, identify those nodes and change the type of conductor between those nodes. Evaluate the output results.

In forth stage, if power loss and the nodes voltage drop are again out of allowable limit, then the optimal placement of the capacitor is carried out. Investigate the output results.

In fifth stage, observe whether the power loss and nodes voltage drop are within the permissible limit or not. If the power loss and node voltage drop are still out of allowable limits then shifting of transformer to its optimal location is carried out. 
The flowchart diagram depicted in Fig.1 delineates all the five stages of the hybrid rehabilitation technique. The modular programming approach has been used for the technique. It is flexible in its application and user can change any input according to his own needs and requirements as and when required. The technique can be implemented through the following steps:

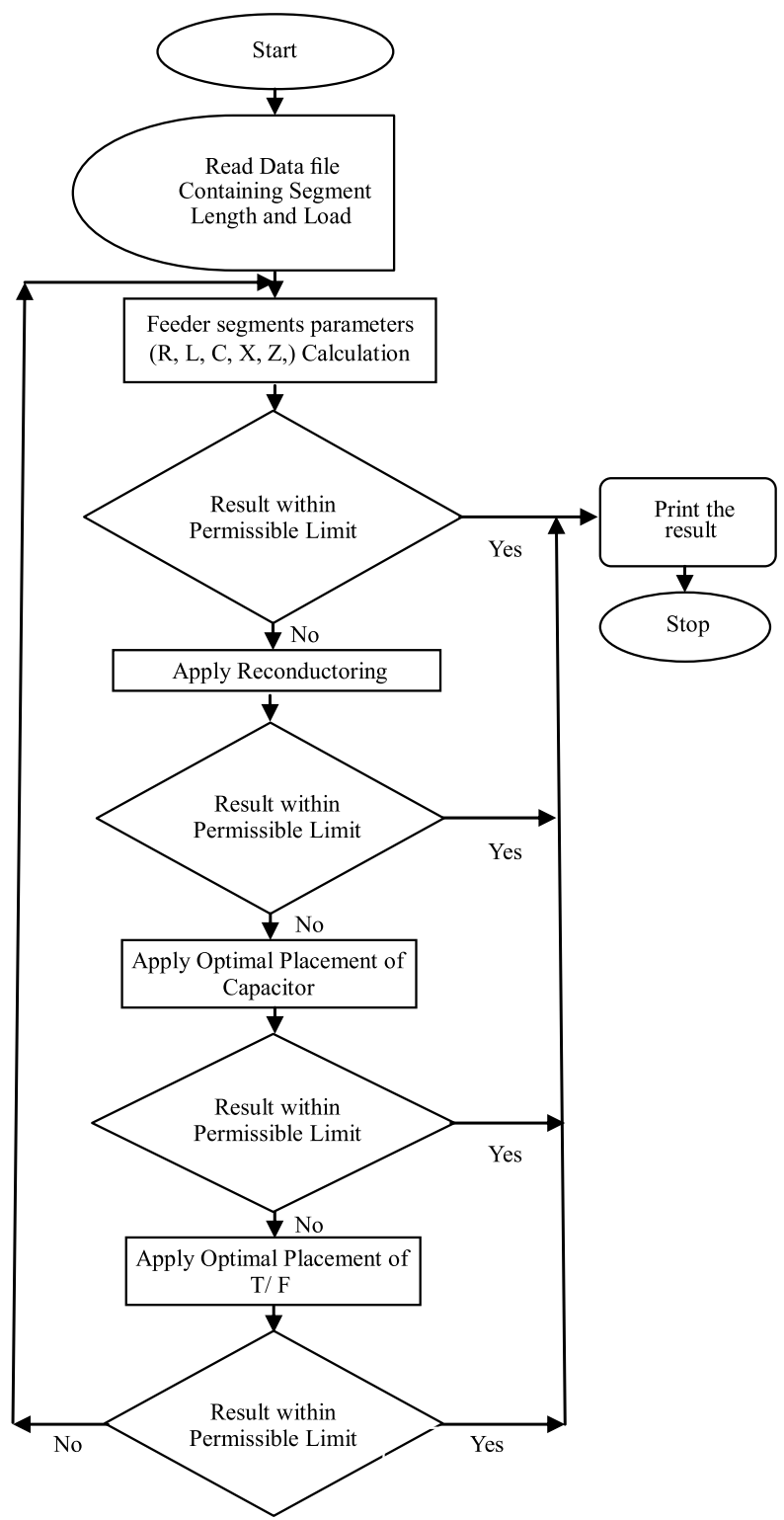

FIG. 1. A FLOW CHART DIAGRAM OF HYBRID REHABILITATION TECHNIQUE USED FOR OPTIMIZATION OF LVDN (i) Choose the problematic low voltage distribution circuit.

(ii) Feed input data on prescribed format.

(iii) Ensured the voltage drop limit $( \pm 5 \%$ of the rated value) for each node.

(iv) If the node voltage drop is out of range, identify such nodes and change the type of conductor between such nodes. Evaluate the node voltage drop.

(v) If the node voltage drop is still out of limit, change the placement of capacitor to its optimal location. Investigate the results.

(vi) If the node voltage drop is again out of range, change the placement of transformer to its optimal location. Observe the limits of node voltage drop.

(vii) If the node voltage drops are still out of permissible limit, repeat the process from step iii to vi until the desired results are obtained.

(viii) Save the results in the data file and take the print.

The hybrid rehabilitation technique can be implemented on any problematic low voltage distribution circuit in a very cost effective manner.

\section{CASE STUDIES}

In this research work, low voltage distribution network of three villages namely Qutab Ferozal, Banth and PothiMandra of Mandra Feeder, Rawilpindi Sub-Division IESCO, Islamabad have been selected as case study. With the help of concerned staff, the data has been collected through actual field survey. The analyses have been carried out by providing the following input data through CADPAD computer software. 
- Length between the successive nodes and type of conductor.

- $\quad$ Load connected in $\mathrm{kVA}$ at each node.

- $\quad$ Rating of installed capacitor if any.

- $\quad$ The maximum value of the current.

- $\quad$ Value of bus voltage.

- Value of existing power factor.

- $\quad$ Value of load factor.

The node is the point on the distribution network at which either a T-off is emanating, a load/transformer is connected or the type of conductor changes. The software generates data base file from the aforementioned data to run the load flow analysis. Based upon the input data, the computer software can automatically performs the following calculations for existing and proposed conditions. However, the system parameters can be modified as and when required.

- $\quad$ Cumulative load connected in kVA at each node.

- Current passing through each segment of the distribution network.

- Percentage load connectedat each section of the distribution network.

- $\quad$ Voltage drop at each node of the distribution network.

- $\quad$ Power loss in each segment of the distribution network in $\mathrm{kW}$.

- Total power loss in the distribution system.

- $\quad$ Total percentage power loss.
Program allows:

- Installation of new capacitor at optimal places of the network.

- Re-conductoring of the identified network segments.

- $\quad$ Shifting of identified transformers to optimal location.

- $\quad$ Segment data modification.

The applied software is very flexible. User can modify/ enhance it as per required parameters because of its modular programming approach. The software program can optimizes solution for LVDN having balance/ unbalance electric loads. The user can feed input data to the software either through keyboard or file depending upon the needs and requirements. After an optimized solution, it calculates total voltage drop and power loss for entire feeder. It can identify the optimal location of capacitor and transformer. On the output, the user can opt to save the output which can be used to generate the graphs and other analyses. The results are tested and verified which are within the permissible limits.

\subsection{Case Study-1}

Applying CADPAD software, load flow analysis of 100 kVA transformer of village Qutab Ferozal has been carried out. Using the available data, the single line diagram of LVDNis generated as shown in Fig. 2. The network consists of 28 nodes. The total length of the circuit is $2.307 \mathrm{kM}$. Data collected through field visits is depicted in Table 1. The number of three phase and single phase consumers are 5 and 157, respectively. The information gathered indicates that ACSR ant conductor with current carrying capacity of 211 amperes has been used. The voltage profile of Fig. 3 delineates that there is a maximum voltage drop of $16 \%$ at node number 25 of the LVDN 
which exceeds the IEEE permissible limit of $\pm 5 \%$. The curve of Fig. 3 indicates that voltage drop up to node number 7 is within the acceptable range for existing system analysis, whereas voltage drop behind node number 7 increases sharply and reaches to maximum value of $16 \%$ at the tail end of the nodes. The voltage profile curve expresses significant improvement in the voltage drop reduction. The application of software proposes the shifting of 100kVA transformer from node number 1 to its optimal location of node number 9 and installation of two capacitors, each of $15 \mathrm{kVAR}$ rating at node number 10 and 18, respectively. The implementation of proposed rehabilitation techniques brings the voltage dropwithin the permissible limit of $\pm 5 \%$ as shown in the proposed voltage profile of Fig.3.

The power curve of existing system is depicted in Fig. 4. Thoroughinvestigation of the curve shows that there is maximum power loss of 2.134, 2.114 and $2.037 \mathrm{~kW}$ at node number 9,8 , and 7 , respectively. The total power loss is $8.314 \mathrm{~kW}$ which has been reduced to $0.8 \mathrm{~kW}$, providing a net saving of $7.541 \mathrm{~kW}$. The maximum power loss at node number 9,8 , and 7 is due to maximum current flow at these nodes.

The energy loss calculations for LVDN of village Qutab Ferozal are shown in Table 2. These calculations are for the period of one month. Total units sent through transformer are $27828 \mathrm{kWh}$. The units consumed through 162 consumers are $15993 \mathrm{kWh}$. The total loss of energy is $11835 \mathrm{kWh}$. The technical loss of energy calculated is $2463 \mathrm{kWh}$. The other loss is $9372 \mathrm{kWh}$. In this way, the percentage of technical loss, other loss and total loss of energy is $8.85,33.68$ and $42.535 \%$, respectively.

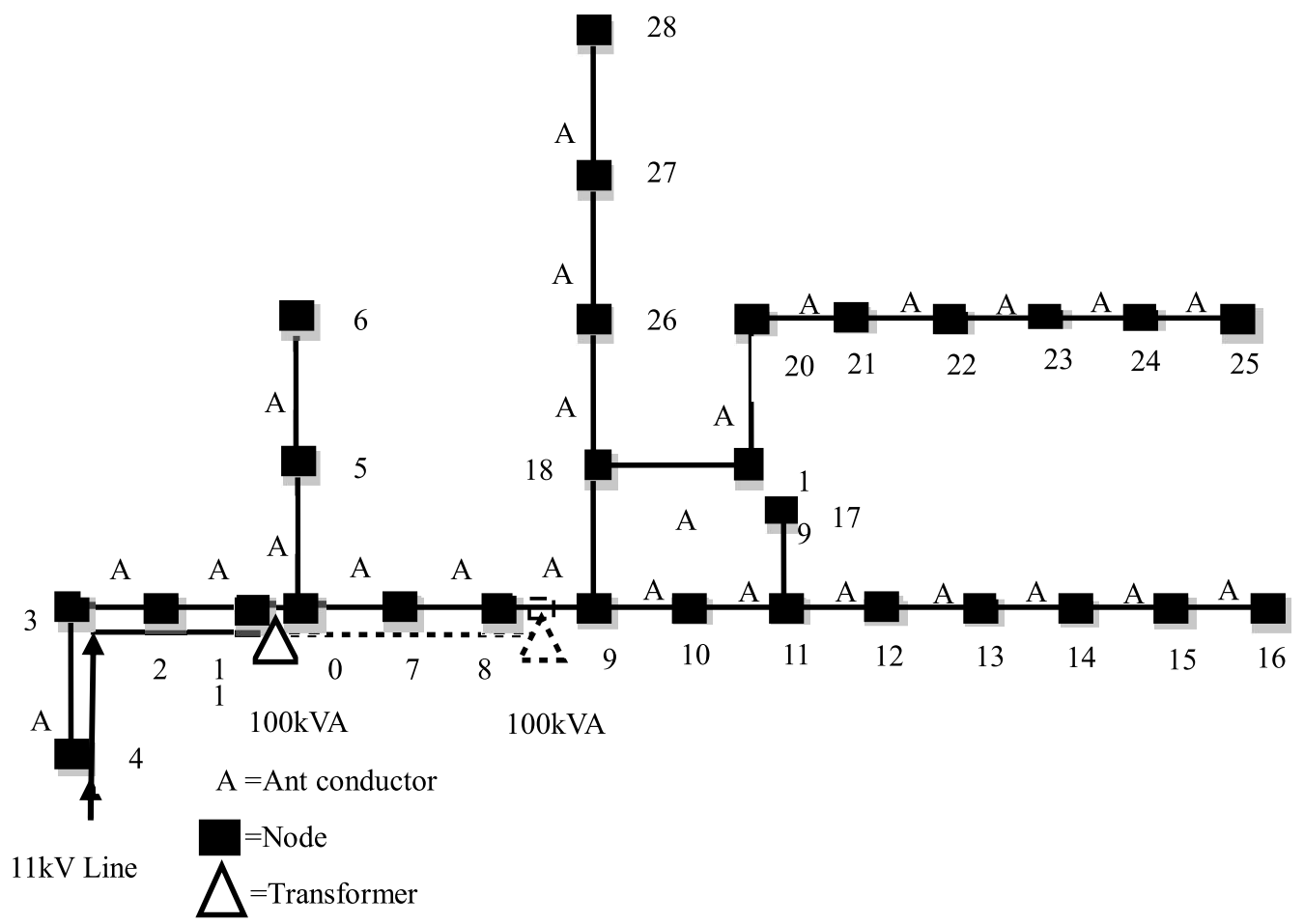

FIG. 2. SINGLE LINE DIAGRAM OF LVDN OF QUTAB FEROZAL, RAWILPINDI SUBDIVISION (PAKISTAN)

Mehran University Research Journal of Engineering \& Technology, Volume 37, No. 3, July, 2018 [p-ISSN: 0254-7821, e-ISSN: 2413-7219] 
TABLE 1. LOAD FLOW ANALYSIS FOR 100KVA TRANSFORMER OF QUTABFEROZAL RAWALPINDI SUBDIVISION IESCO ISLAMABAD (PAKISTAN)

\begin{tabular}{|c|c|c|c|c|c|c|c|c|c|c|c|c|c|}
\hline \multicolumn{2}{|c|}{ Node } & \multirow{2}{*}{$\begin{array}{c}\text { Section } \\
\text { Length } \\
(\mathrm{kM})\end{array}$} & \multirow{2}{*}{$\begin{array}{c}\text { 3- } \phi \\
\text { Load } \\
\text { (kVA) }\end{array}$} & \multirow{2}{*}{$\begin{array}{c}1-\phi \\
\text { Cons } \\
k V A\end{array}$} & \multirow[b]{2}{*}{ kVA } & \multirow[b]{2}{*}{$\begin{array}{c}\text { Cumulative } \\
\mathrm{kVA}\end{array}$} & \multirow[b]{2}{*}{ Conductor } & \multirow[b]{2}{*}{ Amperes } & \multirow[b]{2}{*}{$\begin{array}{r}\text { Load } \\
(\%)\end{array}$} & \multirow{2}{*}{$\begin{array}{c}\text { Voltage } \\
\text { Drop } \\
(\%)\end{array}$} & \multirow{2}{*}{$\begin{array}{c}\text { Voltage } \\
\text { Drop } \\
\text { (prop) } \\
(\%)\end{array}$} & \multirow[b]{2}{*}{$\begin{array}{c}\text { P.Loss } \\
(\%)\end{array}$} & \multirow{2}{*}{$\begin{array}{r}\text { P.Loss } \\
\text { (prop) } \\
(\%)\end{array}$} \\
\hline From & To & & & & & & & & & & & & \\
\hline 0 & 1 & 0.002 & 0 & 2 & 1.00 & 82.00 & A & 145.0 & 69 & 0.1 & 0.1 & 0.084 & 0.004 \\
\hline 1 & 2 & 0.076 & 0 & 5 & 2.50 & 10.00 & A & 17.7 & 8 & 0.5 & 0.5 & 0.048 & 0.004 \\
\hline 1 & 5 & 0.091 & 0 & 3 & 1.50 & 9.00 & A & 15.9 & 8 & 0.6 & 0.6 & 0.046 & 0.003 \\
\hline 1 & 7 & 0.085 & 0 & 2 & 1.00 & 62.00 & A & 109.6 & 52 & 3.2 & 3.2 & 2.037 & 0.050 \\
\hline 2 & 3 & 0.073 & 2 & 8 & 5.00 & 7.50 & A & 13.3 & 6 & 0.8 & 0.8 & 0.026 & 0.005 \\
\hline 3 & 4 & 0.084 & 0 & 5 & 2.50 & 2.50 & A & 4.4 & 2 & 0.9 & 0.9 & 0.003 & 0.003 \\
\hline 5 & 6 & 0.091 & 3 & 10 & 7.50 & 7.50 & A & 13.3 & 6 & 1.0 & 1.0 & 0.032 & 0.032 \\
\hline 7 & 8 & 0.091 & 0 & 2 & 1.00 & 61.00 & A & 107.9 & 51 & 6.5 & 4.5 & 2.114 & 0.004 \\
\hline 8 & 9 & 0.095 & 0 & 10 & 5.00 & 60.00 & A & 106.1 & 50 & 9.9 & 4.9 & 2.134 & 0.003 \\
\hline 9 & 10 & 0.085 & 0 & 5 & 2.50 & 17.50 & A & 30.9 & 15 & 10.8 & 4.9 & 0.162 & 0.002 \\
\hline 9 & 18 & 0.061 & 0 & 8 & 4.00 & 37.50 & A & 66.3 & 31 & 11.2 & 4.8 & 0.535 & 0.080 \\
\hline 10 & 11 & 0.088 & 0 & 6 & 3.00 & 15.00 & A & 26.5 & 13 & 11.6 & 4.5 & 0.123 & 0.040 \\
\hline 11 & 12 & 0.085 & 0 & 10 & 5.00 & 10.00 & A & 17.7 & 8 & 12.1 & 4.9 & 0.053 & 0.040 \\
\hline 11 & 17 & 0.061 & 0 & 4 & 2.00 & 2.00 & A & 3.5 & 2 & 11.7 & 4.8 & 0.001 & 0.001 \\
\hline 12 & 13 & 0.055 & 0 & 3 & 1.50 & 5.00 & A & 8.8 & 4 & 12.3 & 4.7 & 0.008 & 0.008 \\
\hline 13 & 14 & 0.088 & 0 & 3 & 1.50 & 3.50 & A & 6.2 & 3 & 12.5 & 4.8 & 0.007 & 0.007 \\
\hline 14 & 15 & 0.088 & 0 & 1 & 0.50 & 2.00 & A & 3.5 & 2 & 12.6 & 4.8 & 0.002 & 0.002 \\
\hline 15 & 16 & 0.088 & 0 & 3 & 1.50 & 1.50 & A & 2.7 & 1 & 12.7 & 4.6 & 0.001 & 0.001 \\
\hline 18 & 19 & 0.095 & 0 & 8 & 4.00 & 23.50 & A & 41.6 & 20 & 12.5 & 4.6 & 0.328 & 0.100 \\
\hline 18 & 26 & 0.098 & 0 & 8 & 4.00 & 10.00 & A & 17.7 & 8 & 11.8 & 4.3 & 0.061 & 0.051 \\
\hline 19 & 20 & 0.091 & 0 & 9 & 4.50 & 19.50 & A & 34.5 & 16 & 13.5 & 4.7 & 0.216 & 0.116 \\
\hline 20 & 21 & 0.091 & 0 & 5 & 2.50 & 15.00 & A & 26.5 & 13 & 14.3 & 4.6 & 0.127 & 0.120 \\
\hline 21 & 22 & 0.088 & 0 & 7 & 3.50 & 12.50 & A & 22.1 & 10 & 14.9 & 5.0 & 0.086 & 0.060 \\
\hline 22 & 23 & 0.085 & 0 & 5 & 2.50 & 9.00 & A & 15.9 & 8 & 15.4 & 5.0 & 0.043 & 0.030 \\
\hline 23 & 24 & 0.095 & 0 & 4 & 2.00 & 6.50 & A & 11.5 & 5 & 15.8 & 4.9 & 0.025 & 0.010 \\
\hline 24 & 25 & 0.091 & 0 & 9 & 4.50 & 4.50 & A & 8.0 & 4 & 16.0 & 4.9 & 0.012 & 0.020 \\
\hline 26 & 27 & 0.091 & 0 & 5 & 2.50 & 6.00 & A & 10.6 & 5 & 12.1 & 4.3 & 0.020 & 0.001 \\
\hline 27 & 28 & 0.095 & 0 & 7 & 3.50 & 3.50 & A & 6.2 & 3 & 12.3 & 4.2 & 0.007 & 0.003 \\
\hline
\end{tabular}




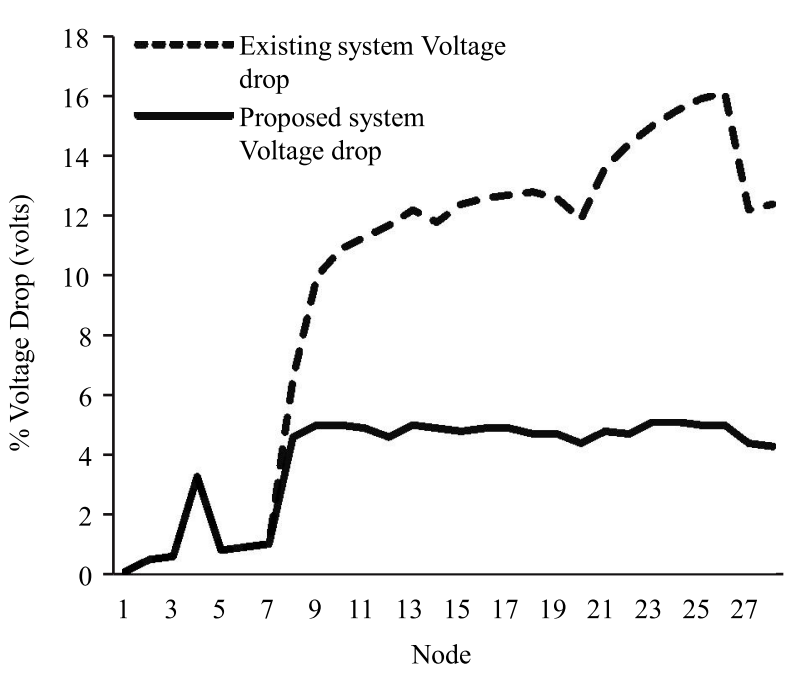

FIG. 3. VOLTAGE PROFILE OF LVDN OF QUTAB FEROZAL, RAWILPINDI SUBDIVISION (PAKISTAN)

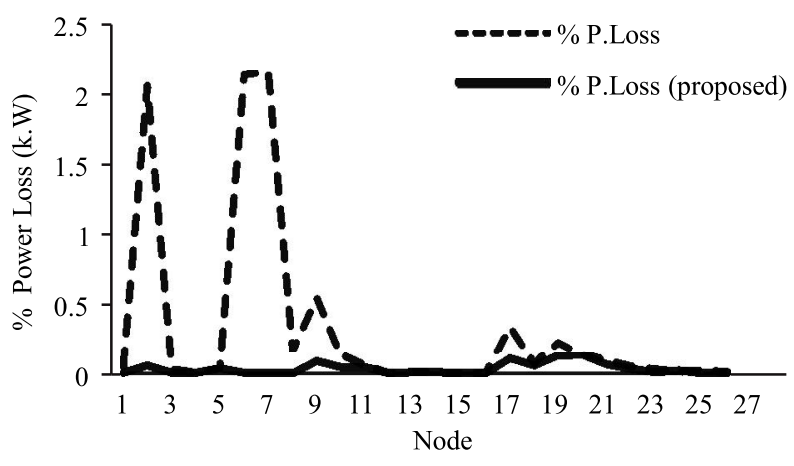

FIG. 4. POWER LOSS CURVE OF LVDN OF QUTAB FEROZAL, RAWILPINDI SUBDIVISION (PAKISTAN)

TABLE 2. ENERGY LOSS CALCULATIONS FOR VILLAGE QUTAB FEROZAL RAWALPINDI SUB-DIVISION (PAKISTAN)

\begin{tabular}{|c|c|c|}
\hline No. & Reading & Units $(\mathrm{kWH})$ \\
\hline 1. & Units sent through transformer & 27828 \\
\hline 2. & Units billed & 15993 \\
\hline 3. & Total loss & 11835 \\
\hline 4. & Technical loss & 2463 \\
\hline 5. & Other loss & 9372 \\
\hline 6. & Technical loss & $8.85 \%$ \\
\hline 7. & Other loss & $33.68 \%$ \\
\hline 8. & Total loss & $42.53 \%$ \\
\hline
\end{tabular}

\subsection{Case Study-2}

The single line diagram of LVDN of village Banth of Mandra Feeder, Rawilpindi Sub-Division IESCO, Islamabad is depicted in Fig. 5. The network consists of 40 numbers of nodes. The total length of the LVDN is $1.713 \mathrm{kM}$. ACSR ant conductor of 211 Ampere current carrying capacity is used up to node number 16 and PVC cable is applied for all rest of the nodes. The data collected by field survey is depicted in Table 3 . The number of three phase and single phase consumers connected with LVDN of 100kVA transformer are 3 and 152, respectively.

The voltage profile of Fig. 6 indicates that there is maximum voltage drop of $10.7,10.6$ and $10.1 \%$ at node number 16 , 15 and 14 respectively. The drop at node number 1-4, 7, 8, 10 , and 24 is within the acceptable range of IEEE $\pm 5 \%$. The voltage drop at all the remaining nodes is beyond the IEEE permissible value. The application of CADPAD software suggested the change of PVC cable to ACSR ant conductor of 211 ampere of current carrying capacity. The re-conductoring of identified nodesbrings the voltage drop within IEEE standard of $\pm 5 \%$. The voltage profile for existing and proposed system is shown in Fig. 6. The power loss curve for existing and proposed system is presented in Fig. 7. The curve indicates the maximum power loss of $0.328 \mathrm{~kW}$ at node number 1 . The maximum flow of load current causes the maximum power loss at initial nodes.

The energy loss calculations for LVDN of village Banth are shown in Table 4. Total units sent through transformer of $100 \mathrm{kVA}$ are $33820 \mathrm{kWh}$. The units charged through 155 consumers are $22687 \mathrm{kWh}$. The total loss of energy is $11133 \mathrm{kWh}$. The technical loss of energy calculated is $872 \mathrm{kWh}$. The other loss is $10261 \mathrm{kWh}$. In this way, the percentage of technical loss, other loss and total loss of energy is $2.58,30.34$ and $32.92 \%$ respectively. 


\subsection{Case Study-3}

The single line diagram of LVDN of village PothiMandra Rawalpindi Sub-Division IESCO, Islamabad is presented in Fig. 8. The circuit is $1.22 \mathrm{kM}$ long, having 22 numbers of nodes. ACSR ant conductor having a current capacity of 211 amperes is used. The data collected through field visit is shown in Table 5. The number of three phase and single phase consumers connected with 100kVA transformer of LVDN are 1 and 179 , respectively.

The voltage profile of LVDN is depicted in Fig. 9. The detailed investigation delineates that there is maximum voltage drop of $15.8,15.7,15.6$, and $15.1 \%$ at node number $15,14,13,12$, and 11, respectively. The voltage at remaining nodes is within the permissible limit of $5 \%$. The implementation of CADPAD software proposes the installation of one number capacitor of $10 \mathrm{kVAR}$ rating at optimal location of node number 10 .
The proposed curve of Fig. 9 indicates that the voltage at all the nodes is within the acceptable limits of $\pm 5 \%$. Power curve of Fig. 10 shows that there is maximum power loss of 0.293 and $0.284 \mathrm{~kW}$ at node number 2 and 3 , respectively. Application of $10 \mathrm{kVAR}$ capacitor reduces power loss to $0.05 \mathrm{~kW}$ or below at all the nodes of LVDN.

The energy loss calculation for LVDN of village PothiMandra has also been carried out for a period of one month. The units sent through transformer were $9851 \mathrm{kWH}$. The units charged through80 consumers connected with the transformer were $7912 \mathrm{kWH}$. Total loss was $1939 \mathrm{kWH}$ and technical losses calculated through the application of software were $143 \mathrm{kWH}$. Other loss was 1796kWH. Percentage of technical loss, other loss and total loss were 1.45, 15.23 and 19.68\%, respectively. The detail of energy loss calculation is presented in Table 6.

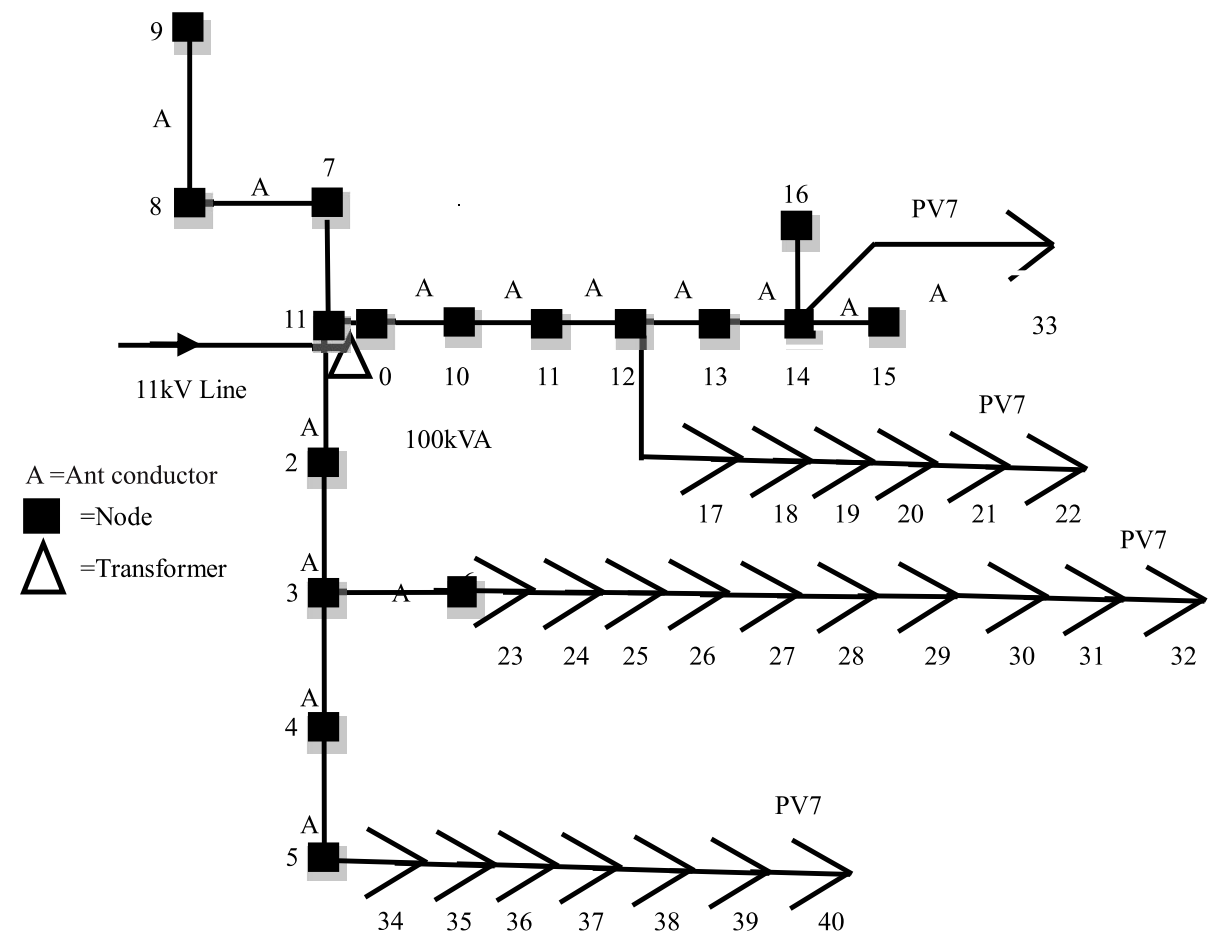

FIG. 5. SINGLE LINE DIAGRAM OF LVDN OF BANTH, RAWILPINDI SUBDIVISION (PAKISTAN)

Mehran University Research Journal of Engineering \& Technology, Volume 37, No. 3, July, 2018 [p-ISSN: 0254-7821, e-ISSN: 2413-7219] 
TABLE 3. LOAD FLOW ANALYSIS FOR 100KVA TRANSFORMER OF BANTH (MANDRA) RAWALPINDI SUBDIVISION IESCO ISLAMABAD (PAKISTAN)

\begin{tabular}{|c|c|c|c|c|c|c|c|c|c|c|c|c|c|}
\hline \multicolumn{2}{|c|}{ Node } & \multirow{2}{*}{$\begin{array}{c}\text { Section } \\
\text { Length } \\
(\mathrm{kM})\end{array}$} & \multirow{2}{*}{$\begin{array}{c}3-\phi \\
\text { Load } \\
(\mathrm{kVA})\end{array}$} & \multirow{2}{*}{$\begin{array}{c}1-\phi \\
\text { Cons } \\
\text { kVA }\end{array}$} & \multirow[b]{2}{*}{$\mathrm{kVA}$} & \multirow[b]{2}{*}{$\begin{array}{c}\text { Cumulative } \\
\mathrm{kVA}\end{array}$} & \multirow[b]{2}{*}{ Conductor } & \multirow[b]{2}{*}{ Amperes } & \multirow[b]{2}{*}{$\begin{array}{r}\text { Load } \\
(\%)\end{array}$} & \multirow{2}{*}{$\begin{array}{c}\text { Voltage } \\
\text { Drop } \\
(\%)\end{array}$} & \multirow{2}{*}{$\begin{array}{c}\text { Voltage } \\
\text { Drop } \\
\text { (prop) } \\
(\%)\end{array}$} & \multirow[b]{2}{*}{$\begin{array}{c}\text { P.Loss } \\
(\%)\end{array}$} & \multirow{2}{*}{$\begin{array}{c}\text { P.Loss } \\
\text { (prop) } \\
(\%)\end{array}$} \\
\hline From & To & & & & & & & & & & & & \\
\hline 0 & 1 & 0.002 & 0 & 0 & 0.00 & 77.00 & $\mathrm{~A}$ & 155.0 & 73 & 0.10 & 0.10 & 0.328 & 0.002 \\
\hline 1 & 2 & 0.085 & 0 & 0 & 0.00 & 29.50 & A & 59.00 & 28 & 1.80 & 1.50 & 0.187 & 0.004 \\
\hline 1 & 7 & 0.061 & 0 & 1 & 0.05 & 8.00 & A & 16.00 & 8 & 0.40 & 0.40 & 0.101 & 0.003 \\
\hline 1 & 10 & 0.082 & 0 & 0 & 0.00 & 40.00 & A & 80.00 & 38 & 2.30 & 1.30 & 0.030 & 0.020 \\
\hline 2 & 3 & 0.088 & 0 & 0 & 0.00 & 11.50 & $\mathrm{~A}$ & 23.00 & 11 & 2.50 & 1.50 & 0.010 & 0.001 \\
\hline 2 & 6 & 0.095 & 0 & 0 & 0.00 & 18.50 & A & 36.00 & 17 & 2.90 & 1.20 & 0.002 & 0.001 \\
\hline 3 & 4 & 0.088 & 0 & 0 & 0.00 & 11.50 & $\mathrm{~A}$ & 23.00 & 11 & 3.20 & 1.00 & 0.123 & 0.020 \\
\hline 4 & 5 & 0.091 & 0 & 0 & 0.00 & 11.50 & A & 23.00 & 11 & 3.90 & 2.90 & 0.112 & 0.010 \\
\hline 5 & 34 & 0.030 & 0 & 2 & 1.00 & 11.50 & PV7 & 23.00 & 72 & 5.90 & 5.00 & 0.054 & 0.040 \\
\hline 6 & 23 & 0.014 & 0 & 2 & 1.00 & 18.00 & PV7 & 36.00 & 113 & 4.30 & 4.00 & 0.034 & 0.030 \\
\hline 7 & 8 & 0.091 & 1 & 6 & 3.00 & 07.50 & A & 15.00 & 7 & 0.90 & 0.50 & 0.016 & 0.010 \\
\hline 8 & 9 & 0.091 & 0 & 8 & 4.00 & 04.00 & $\mathrm{~A}$ & 08.00 & 4 & 1.10 & 1.00 & 0.007 & 0.005 \\
\hline 10 & 11 & 0.088 & 0 & 0 & 0.00 & 40.00 & A & 80.00 & 38 & 4.60 & 4.00 & 0.139 & 0.130 \\
\hline 11 & 12 & 0.085 & 2 & 8 & 4.00 & 40.00 & A & 80.00 & 38 & 6.90 & 5.00 & 0.098 & 0.080 \\
\hline 12 & 13 & 0.091 & 0 & 5 & 2.50 & 27.50 & A & 55.00 & 26 & 8.60 & 4.50 & 0.129 & 0.020 \\
\hline 12 & 17 & 0.018 & 0 & 2 & 1.00 & 7.50 & PV7 & 15.00 & 47 & 7.70 & 5.00 & 0.158 & 0.150 \\
\hline 13 & 14 & 0.091 & 0 & 0 & 0.00 & 25.00 & A & 05.00 & 24 & 10.1 & 4.50 & 0.012 & 0.010 \\
\hline 14 & 15 & 0.095 & 0 & 15 & 7.50 & 07.50 & A & 15.00 & 7 & 10.6 & 4.30 & 0.143 & 0.040 \\
\hline 14 & 16 & 0.095 & 0 & 20 & 10.00 & 10.00 & A & 20.00 & 9 & 10.7 & 5.00 & 0.069 & 0.060 \\
\hline 14 & 33 & 0.095 & 0 & 15 & 7.50 & 07.50 & A & 15.00 & 7 & 10.6 & 4.00 & 0.137 & 0.130 \\
\hline 17 & 18 & 0.012 & 0 & 1 & 0.50 & 06.50 & PV7 & 13.00 & 41 & 8.10 & 3.50 & 0.127 & 0.120 \\
\hline 18 & 19 & 0.012 & 0 & 3 & 1.50 & 06.00 & PV7 & 12.00 & 38 & 8.50 & 5.00 & 0.038 & 0.035 \\
\hline 19 & 20 & 0.009 & 0 & 4 & 2.00 & 04.50 & PV7 & 09.00 & 28 & 8.70 & 4.10 & 0.069 & 0.065 \\
\hline 20 & 21 & 0.018 & 0 & 3 & 1.50 & 02.50 & PV7 & 05.00 & 16 & 9.00 & 4.30 & 0.153 & 0.006 \\
\hline 21 & 22 & 0.009 & 0 & 2 & 1.00 & 01.00 & PV7 & 02.00 & 6 & 9.10 & 5.00 & 0.155 & 0.003 \\
\hline 23 & 24 & 0.006 & 0 & 3 & 1.50 & 17.00 & PV7 & 34.00 & 106 & 4.90 & 4.50 & 0.123 & 0.004 \\
\hline 24 & 25 & 0.009 & 0 & 1 & 0.50 & 15.50 & PV7 & 31.00 & 97 & 5.70 & 5.00 & 0.036 & 0.006 \\
\hline 25 & 26 & 0.014 & 0 & 2 & 1.00 & 15.00 & PV7 & 30.00 & 94 & 6.90 & 4.00 & 0.019 & 0.005 \\
\hline 26 & 27 & 0.018 & 0 & 4 & 2.0 & 14.00 & PV7 & 28 & 88 & 8.3 & 5.00 & 0.328 & 0.050 \\
\hline 27 & 28 & 0.014 & 0 & 5 & 2.5 & 12.00 & PV7 & 24 & 75 & 9.3 & 3.00 & 0.187 & 0.008 \\
\hline 28 & 29 & 0.012 & 0 & 7 & 3.5 & 9.5 & PV7 & 19 & 59 & 9.9 & 3.50 & 0.101 & 0.010 \\
\hline 29 & 30 & 0.009 & 0 & 5 & 2.5 & 6.0 & PV7 & 12 & 38 & 10.2 & 3.80 & 0.030 & 0.007 \\
\hline 30 & 31 & 0.009 & 0 & 4 & 2.0 & 3.5 & PV7 & 7 & 22 & 10.4 & 4.50 & 0.010 & 0.006 \\
\hline 31 & 32 & 0.009 & 0 & 3 & 1.5 & 1.5 & PV7 & 3 & 9 & 10.5 & 4.80 & 0.002 & 0.001 \\
\hline 34 & 35 & 0.012 & 0 & 1 & 0.5 & 0.5 & PV7 & 21 & 66 & 6.6 & 5.00 & 0.123 & 0.003 \\
\hline 35 & 36 & 0.012 & 0 & 4 & 2.0 & 2.0 & PV7 & 20 & 63 & 7.3 & 2.40 & 0.112 & 0.012 \\
\hline 36 & 37 & 0.009 & 0 & 5 & 2.5 & 2.5 & PV7 & 16 & 50 & 7.7 & 2.00 & 0.054 & 0.020 \\
\hline 37 & 38 & 0.012 & 0 & 4 & 2.0 & 2.0 & PV7 & 11 & 34 & 8.1 & 5.00 & 0.034 & 0.010 \\
\hline 38 & 39 & 0.014 & 0 & 3 & 1.5 & 1.5 & PV7 & 7 & 22 & 8.4 & 4.50 & 0.016 & 0.005 \\
\hline 39 & 40 & 0.018 & 0 & 4 & 2.0 & 2.00 & PV7 & 4 & 13 & 8.6 & 5.00 & 0.007 & 0.005 \\
\hline
\end{tabular}




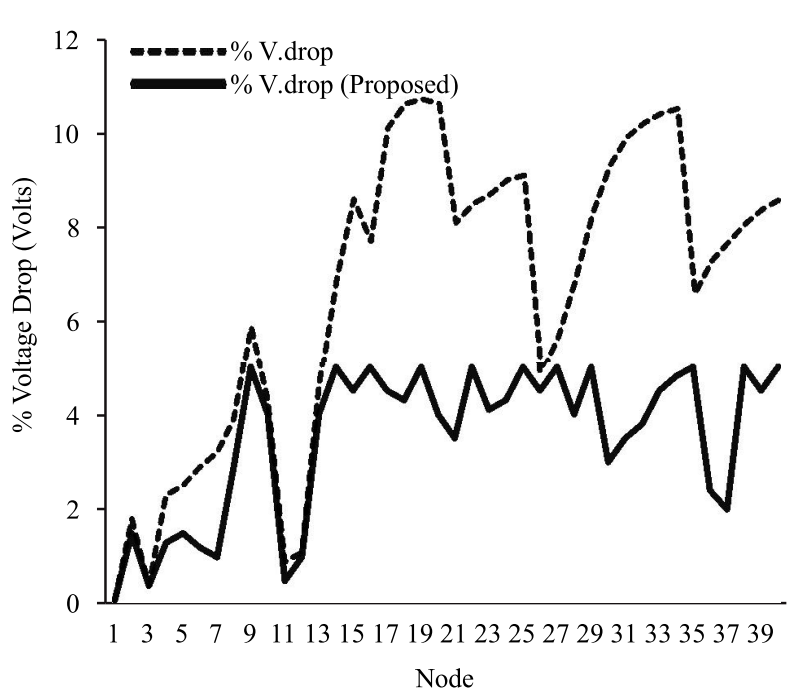

FIG. 6. VOLTAGE PROFILE OF LVDN OF BANTH, RAWILPINDI SUBDIVISION (PAKISTAN)

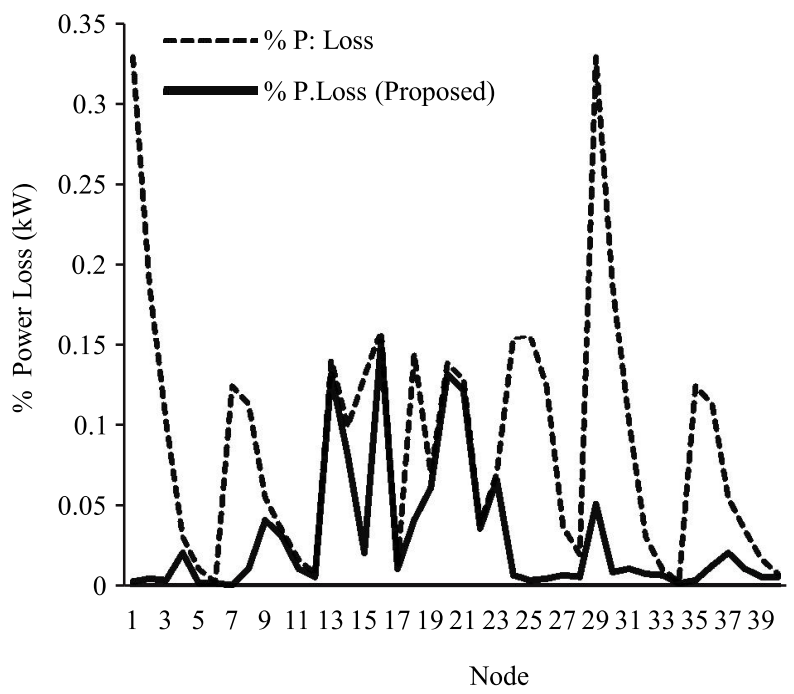

FIG. 7. POWER LOSS CURVE OF LVDN OF BANTH, RAWILPINDI SUBDIVISION (PAKISTAN)

TABLE 4. ENERGY LOSS CALCULATIONS FOR VILLAGE BANTH (MANDRA) RAWALPINDI (PAKISTAN)

\begin{tabular}{|c|c|c|}
\hline No. & Reading & Units $(\mathrm{kWH})$ \\
\hline 1. & Units sent through transformer & 33820 \\
\hline 2. & Units billed & 22687 \\
\hline 3. & Total loss & 11133 \\
\hline 4. & Technical loss & 872 \\
\hline 5. & Other loss & 10261 \\
\hline 6. & Technical loss & $2.58 \%$ \\
\hline 7. & Other loss & $30.34 \%$ \\
\hline 8. & Total loss & $32.92 \%$ \\
\hline
\end{tabular}

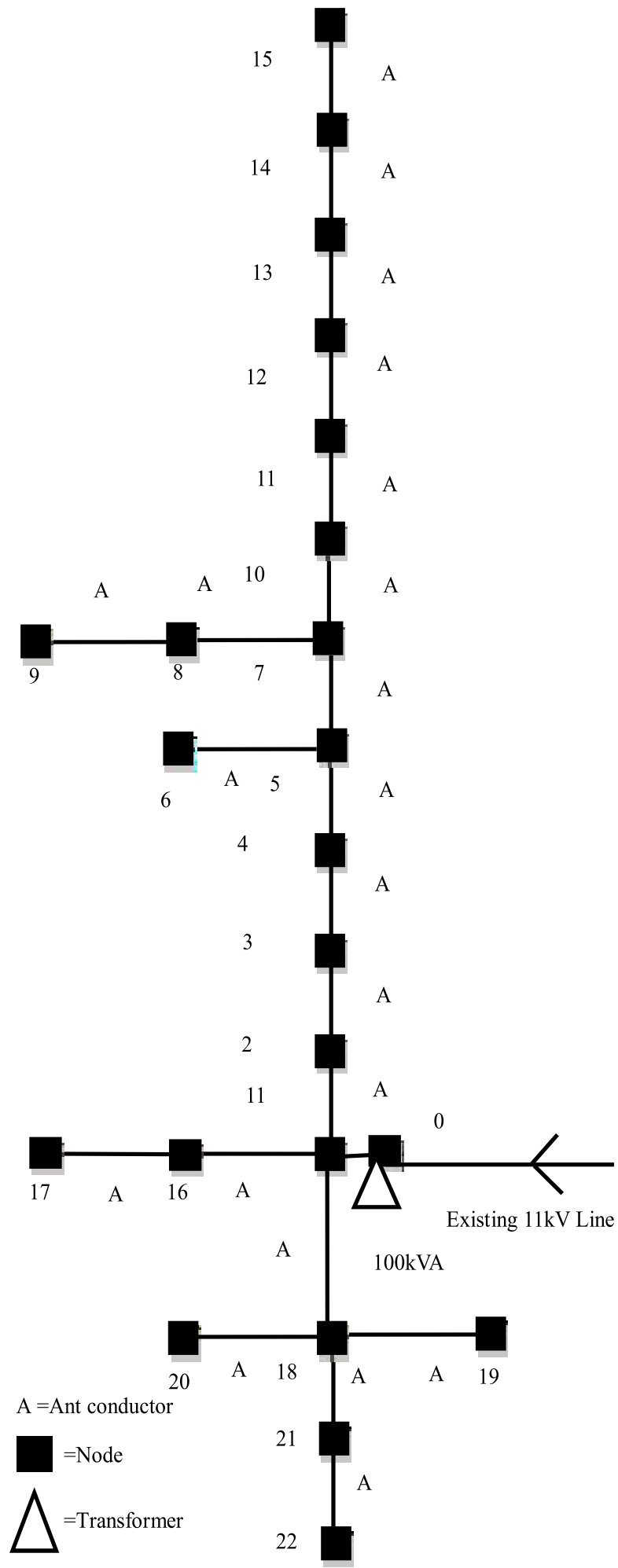

FIG. 8. SINGLE LINE DIAGRAM OF LVDN OF POTHIMANDRA, RAWILPINDI SUBDIVISION (PAKISTAN)

Mehran University Research Journal of Engineering \& Technology, Volume 37, No. 3, July, 2018 [p-ISSN: 0254-7821, e-ISSN: 2413-7219] 
TABLE 5. LOAD FLOW ANALYSIS FOR 100KVA TRANSFORMER OF POTHI(MANDRA) RAWALPINDI SUBDIVISION IESCO ISLAMABAD (PAKISTAN)

\begin{tabular}{|c|c|c|c|c|c|c|c|c|c|c|c|c|c|}
\hline \multicolumn{2}{|c|}{ Node } & \multirow{2}{*}{$\begin{array}{c}\text { Section } \\
\text { Length } \\
(\mathrm{kM})\end{array}$} & \multirow{2}{*}{$\begin{array}{c}\text { 3- } \phi \\
\text { Load } \\
\text { (kVA) }\end{array}$} & \multirow{2}{*}{$\begin{array}{c}1-\phi \\
\text { Cons } \\
\text { kVA }\end{array}$} & \multirow[b]{2}{*}{ kVA } & \multirow[b]{2}{*}{$\begin{array}{c}\text { Cumulative } \\
\mathrm{kVA}\end{array}$} & \multirow[b]{2}{*}{ Conductor } & \multirow[b]{2}{*}{ Amperes } & \multirow[b]{2}{*}{$\begin{array}{r}\text { Load } \\
(\%)\end{array}$} & \multirow{2}{*}{$\begin{array}{c}\text { Voltage } \\
\text { Drop } \\
(\%)\end{array}$} & \multirow{2}{*}{$\begin{array}{c}\text { Voltage } \\
\text { Drop } \\
\text { (prop) } \\
(\%)\end{array}$} & \multirow[b]{2}{*}{$\begin{array}{c}\text { P.Loss } \\
(\%)\end{array}$} & \multirow{2}{*}{$\begin{array}{c}\text { P.Loss } \\
\text { (prop) } \\
(\%)\end{array}$} \\
\hline From & To & & & & & & & & & & & & \\
\hline 0 & 1 & 0.002 & 0 & 0 & 0.0 & 39.5 & A & 57.0 & 27 & 0.0 & 0.0 & 0.013 & 0.012 \\
\hline 1 & 2 & 0.061 & 0 & 1 & 0.5 & 34.0 & A & 49.1 & 23 & 1.0 & 1.0 & 0.293 & 0.009 \\
\hline 1 & 16 & 0.061 & 0 & 4 & 2.0 & 3.5 & A & 5.1 & 2 & 0.1 & 0.1 & 0.003 & 0.001 \\
\hline 1 & 18 & 0.061 & 0 & 0 & 0.00 & 2.0 & A & 2.9 & 1 & 0.1 & 0.1 & 0.001 & 0.001 \\
\hline 2 & 3 & 0.061 & 1 & 9 & 4.5 & 33.5 & A & 48.3 & 23 & 0.2 & 0.2 & 0.284 & 0.003 \\
\hline 3 & 4 & 0.058 & 0 & 3 & 1.5 & 28.5 & A & 41.1 & 19 & 2.8 & 2.5 & 0.195 & 0.050 \\
\hline 4 & 5 & 0.055 & 0 & 5 & 2.5 & 27.0 & A & 39.0 & 18 & 3.5 & 3.0 & 0.167 & 0.007 \\
\hline 5 & 6 & 0.058 & 0 & 2 & 1.0 & 1.0 & A & 1.4 & 1 & 3.5 & 3.1 & 0.000 & 0.000 \\
\hline 5 & 7 & 0.061 & 0 & 1 & 0.5 & 23.5 & A & 33.9 & 16 & 4.2 & 4.0 & 0.140 & 0.010 \\
\hline 7 & 8 & 0.058 & 0 & 3 & 1.5 & 4.0 & A & 5.8 & 3 & 4.3 & 4.1 & 0.004 & 0.003 \\
\hline 7 & 10 & 0.058 & 0 & 8 & 4.0 & 19.0 & A & 27.4 & 13 & 4.7 & 4.2 & 0.087 & 0.050 \\
\hline 8 & 9 & 0.055 & 0 & 5 & 2.5 & 2.5 & A & 3.6 & 2 & 4.4 & 4.3 & 0.001 & 0.001 \\
\hline 10 & 11 & 0.061 & 0 & 10 & 5.0 & 15.0 & A & 21.6 & 10 & 15.1 & 5.0 & 0.057 & 0.050 \\
\hline 11 & 12 & 0.058 & 0 & 8 & 4.0 & 10.0 & A & 14.4 & 7 & 15.4 & 4.5 & 0.024 & 0.020 \\
\hline 12 & 13 & 0.058 & 0 & 5 & 2.5 & 6.0 & A & 8.7 & 4 & 15.6 & 5.0 & 0.009 & 0.005 \\
\hline 13 & 14 & 0.055 & 0 & 3 & 1.5 & 3.5 & A & 5.1 & 2 & 15.7 & 4.2 & 0.003 & 0.002 \\
\hline 14 & 15 & 0.058 & 0 & 4 & 2.0 & 2.0 & A & 2.9 & 1 & 15.8 & 4.0 & 0.001 & 0.001 \\
\hline 16 & 17 & 0.055 & 0 & 3 & 1.5 & 1.5 & A & 2.2 & 1 & 0.1 & 0.1 & 0.001 & 0.001 \\
\hline 18 & 19 & 0.058 & 0 & 1 & 0.5 & 0.5 & A & 0.7 & 0 & 0.1 & 0.1 & 0.000 & 0.000 \\
\hline 18 & 20 & 0.005 & 0 & 1 & 0.5 & 0.5 & A & 0.7 & 0 & 0.1 & 0.1 & 0.000 & 0.000 \\
\hline 18 & 21 & 0.005 & 0 & 1 & 0.00 & 1.0 & A & 1.4 & 1 & 4.5 & 4.0 & 0.000 & 0.000 \\
\hline 21 & 22 & 0.058 & 0 & 2 & 1.00 & 1.0 & A & 1.4 & 1 & 5.0 & 4.8 & 0.000 & 0.000 \\
\hline 21 & & & 0 & & & & A & & & 5.6 & 5.0 & & \\
\hline
\end{tabular}




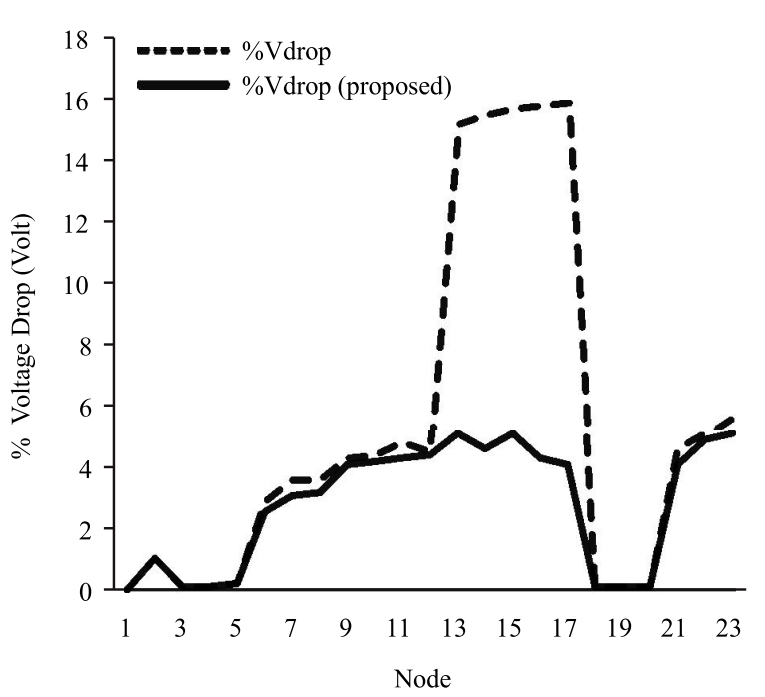

FIG. 9. VOLTAGE PROFILE OF LVDN OF POTHI-MANDRA, RAWILPINDI SUBDIVISION (PAKISTAN)

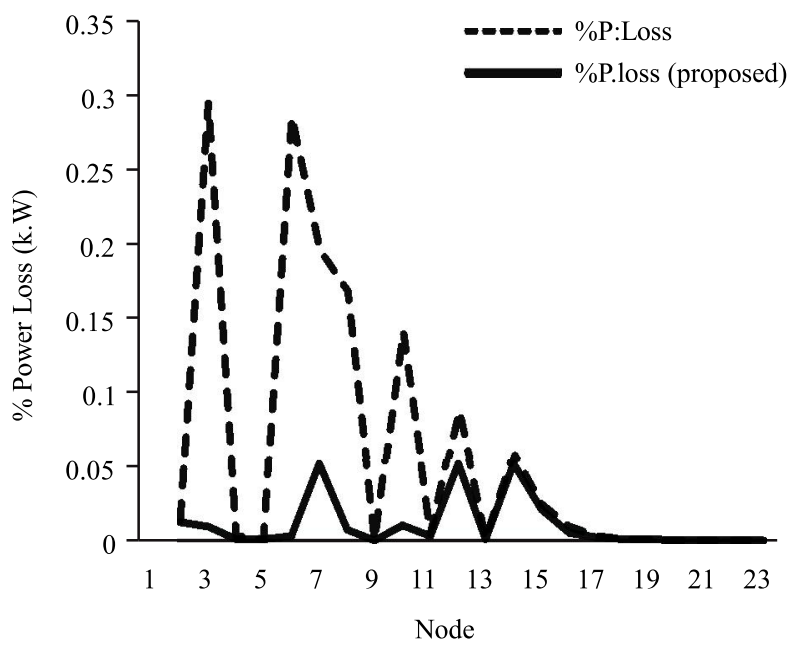

FIG. 10. POWER LOSS CURVE OF LVDN OF POTHIMANDRA, RAWILPINDI SUBDIVISION (PAKISTAN).

TABLE 6. ENERGY LOSS CALCULATIONS FOR VILLAGE BANTH (MANDRA) RAWALPINDI SUBDIVISION (PAKISTAN)

\begin{tabular}{|c|c|c|}
\hline No. & Reading & Units (kWH) \\
\hline 1. & Units sent through transformer & 9851 \\
\hline 2. & Units billed & 7912 \\
\hline 3. & Total loss & 1939 \\
\hline 4. & Technical loss & 143 \\
\hline 5. & Other loss & 1796 \\
\hline 6. & Technical loss & $1.45 \%$ \\
\hline 7. & Other loss & $15.23 \%$ \\
\hline 8. & Total loss & $19.68 \%$ \\
\hline
\end{tabular}

\section{CONCLUSION}

In the competitive and deregulated environment, electric utilities particularly belonging to developing countries are facing the energy crises throughout the world. This research paper proposesan innovative hybrid rehabilitation technique for problematic LVDN. Nonuniform distribution of load, varying power factor, loose joints, leakage current and the use of low current carrying capacity conductors are primarily responsible for voltage drop and power loss in low voltage distribution networks.

Three different overloaded LVDN have been analyzed, using the hybrid rehabilitation technique. The elaborative results are presented in the case studies. These results are verified and are within the permissible limits. Because of modular programming approach, the technique is simple in structure, flexible and easy to implement. Load forecasts are made on the basis of load data. Majority of the data collected is based on the information provided by the customer's application forms which is usually not $100 \%$ accurate. On the basis of incorrect data, the complexities arise during the design of LVDN.The hybrid rehabilitation technique can calculate different segments data automatically. The application of technique not only eliminates the problem of node voltage drop and power loss but significantly increases the stability of such LVDN. Results in the case studies delineates that the technique can be applied both for identifying the problematic nodes as well as the optimal placement of capacitors and distribution transformers. The technique can be utilized effectively to enhance the performance of LVDN. The end customers can be benefited significantly by integrating the technique with LVDN. 


\section{NOMENCLATURE}

$\begin{array}{ll}\text { AMI } & \text { Advance Metering Infrastructure } \\ \text { ALT } & \text { Automatic Load Transfer } \\ \text { DFR } & \text { Distribution Feeder Reconfiguration } \\ \Delta \mathrm{P}_{\mathrm{TF}} & \text { Power loss in Distribution Transformer } \\ \Delta \mathrm{P} & \text { Overall Power Loss } \\ \mathrm{P}_{\text {loss }} & \text { The Total Power Loss for " } \mathrm{n} \text { " Segment } \\ \mathrm{R}_{\mathrm{i}} & \text { Resistance of the } \mathrm{i}^{\text {th }} \mathrm{Transformer} \\ \mathrm{R}_{\mathrm{j}} & \text { Resistance of } \mathrm{j} \text { 'Branch. } \\ \mathrm{N}_{\mathrm{b}} & \text { Branches of Distribution Network } \\ \mathrm{I}_{\mathrm{i}}, \mathrm{I}_{\mathrm{j}} & \text { The Relevant Currents }\end{array}$

CADPAD Computer Aided Distribution Planning and Design

ELR Energy Loss Reduction

EPDS Electric Power Distribution System

IESCO Islamabad Electricity Supply Corporation.

IEEE Institute of Electrical and Electronic Engineering

LVDN Low Voltage Distribution Networks

$\mathrm{L}_{\mathrm{i}} \quad$ Supplied Load at $\mathrm{i}^{\text {th }}$ Node per Unit

$\mathrm{N} \quad$ Number of the Nodes.

$\mathrm{V}$ (nom) Nominal Voltage per Unit

$\mathrm{V}(\max ) \quad$ Maximum Voltage per Unit

$\mathrm{V}(\mathrm{min}) \quad$ Minimum Voltage per Unit

VP1 Voltage Profile Improvement

$\mathrm{V}_{\mathrm{i}} \quad$ Any Voltage per Unit at $i^{\text {th }}$ Node

$\mathrm{V}_{\mathrm{s}} \quad$ Sending End Voltage of the Distribution Network.

$\mathrm{V}_{\text {drop }} \quad$ Total Voltage Drop

$\mathrm{V}_{\mathrm{r}} \quad$ Receiving End Voltage of the Distribution Network

$\mathrm{VP}_{2 \mathrm{i}} \quad$ Voltage Profile at $\mathrm{i}^{\text {th }}$ Node with $\mathrm{W}_{\mathrm{i}}$

$\mathrm{W}_{\mathrm{i}} \quad$ Weighting Factor

WAPDA Water and Power Development Authority

\section{ACKNOWLEDGEMENT}

The authors are thankful to KP-TEVTA Department, who are kind enough to allow us to complete this research work. Authors also appreciate the valuable assistance and guidance of Superintending Engineer Abbottabad WAPDA, without whose help, we were unable to complete this task successfully.

\section{REFERENCES}

[1] Kalambe, S., and Agnihotri, G., "Loss Minimization Techniques Used in Distribution Network: Bibliographical Survey”, Renewable and Sustainable Energy Reviews, Volume 29, pp. 184-200, Netherlands, 2014.

[2] Huang, S., Wu, Q., Cheng, L., and Liu, Z., "Optimal Reconfiguration-Based Dynamic Tariff for Congestion Management and Line Loss Reduction in Distribution Networks", IEEE Transaction on Smart Grid, Volume 7, No. 3, pp. 1295-1303, USA, 2016.

[3] Askarzadeh, A., "Capacitor Placement in the Distribution Systems for Power Loss Reduction and Voltage Improvement: A New Methodology", IET Generation, Transmission and Distribution, Volume 10, No. 14, pp. 3631-3638, India, 2016.

Bai, X., Mavrocostanti, Y., Starikland, D., and Harrap, C., "Distribution Network Reconfiguration Validation with Uncertain Loads-Network Configuration Determination and Application", IET Generation, Transmission and Distribution, Volume 10, No. 12, pp. 2852-2860, India, 2016.

Sayed, M.,and Takeshita, T., "Line Loss Minimization in Isolated Substations and Multiple Loop Distribution Systems Using the UPFC", IEEE Transaction on Power Electronics, Volume 29, No. 11, pp. 5813-5821, USA, 2014.

Mehran University Research Journal of Engineering \& Technology, Volume 37, No. 3, July, 2018 [p-ISSN: 0254-7821, e-ISSN: 2413-7219] 
[6] Melodi, A.O., and Ogunboyo, P.T., "Power Distribution Problems on $11 \mathrm{kV}$ Feeder Networks in Akure", IEEE International Conference on Emerging \& Sustainable Technologies for Power \& ICT in a Developing Society, pp. 292-300, Nigeria, 2013.

[7] Narimani, M.R., Vahed, A.A., Azizipanah-Abarghooee, R., and Javidsharifi, M., "Enhanced Gravitational Search Algorithm for Multi-Objective Distribution Feeder Reconfiguration Considering Reliability, Loss and Operational Cost", IET Generation, Transmission \& Distribution, Volume 8, No. 1, pp. 55-69, India, 2013.

[8] Ozgonenel, O., Karagol, S., and Terzi, U.K., "Novel Approach for Distributed Renewable Generation and Shunt Capacitor placing in the Smart-Grid", 5th IEEE PES Innovative Smart Grid Technologies Europe, pp. 1-6, Turkey, 2014.

[9] Kumar, R.S., Raghunatha, T., and Deshpande, R.A., "Segregation of Technical and Commercial Losses in an $11 \mathrm{kV}$ Feeder", IEEE GCC Conference and Exhibition, pp. 76-79, Qatar, 2013.

[10] Murthy, K.V.S.R., and Raju, M.R., "Electrical Energy Loss in Rural Distribution Feeders: A Case Study", ARPN Journal of Engineering and Applied Science, Volume 4, pp. 33-37, Pakistan, 2009.

[11] Balakrishna, P., Rajagopal, K., and Swarup, K.S., "Application Benefits of Distribution Automation and AMI Systems Convergence Methodology for Distribution Power Restoration Analysis", Sustainable Energy, Grids and Networks, Volume 2, pp. 15-22, India, 2015.

[12] Totare, N.P., and Pandit, S., "Power Sector Reform in Masharashtra, India", Energy Policy, Volume 38, pp. 7082-7092, India, 2010.

[13] Khan, H., "Performance Improvement in Distribution Feeder by Installing Distributed Generation at Strategic Locations", IEEE-ICET $2^{\text {nd }}$ International Conference on Emerging Technologies, pp. 403-407, Pakistan, 2006.
[14] Zehra, E.J, Moghavvemi, M., Hashim, M.M.I., and Muttaqi, K., "Network Reconfiguration Using PSAT for Loss Reduction in Distribution Systems", $1^{\text {st }}$ International Conference on Energy, Power and Control, pp. 62-66, Iraq, 2010.

[15] Mekhilef, S., Chard, T.R., and Ramachandramurthy, V.K., "Voltage Rise Due to Inter-Connection of Embedded Generators to Distribution Network", Journal of Scientific and Industrial Research, Volume 69, pp. 433-438, Malaysia, 2010.

[16] Khare, A., Bajpai, S.K., and Choubey, M., "Restructuring of $11 / 0.4 \mathrm{kV}$ Distribution Network of JNKVV Jabalpur to Minimize Losses and Demand", International Conference on Communication Systems and Network Technologies, pp. 817-820, India, 2013.

[17] Murthy, K.V.S.R., Manikanta, K., and Phanindra, G.V., "Analysis of Low Tension Agricultural Distribution Systems",Internal Journal of Engineering and Technology, Volume 2, No. 3, pp. 334-342, India, 2012.

[18] Gallego, R.A., and Monticelli, R.A.J., "Optimal Capacitor Placement in Radial Distribution Networks", IEEE Transactions on Power System, Volume 16, No. 4, pp. 630-637, USA, 2001.

[19] Carpinelli, G., Noce, C., Russo, A., and Varilone, P., "Trade Off Methods for Capacitor Placement in Unbalance Distribution Systems", International Conference on Future Power Systems, Italy, 2005.

[20] Zidan, A., and El-Saadany, E.F., "Distribution System Reconfiguration for Energy Loss Reduction Considering the Variability of Load and Local Renewable Generation”, Energy Journal, Volume 59, pp. 698-707, Netherlands, 2013.

[21] Lin, W.M., and Chin, H.C., "A New Approach for Distribution Feeder Reconfiguration for Loss Reduction and Service Restoration", IEEE Transaction on Power Delivery, Volume 13, No. 3, pp. 870-875, USA, 1998. 
[22] Mohsin, Q. K., Lin, X., Flaih, F.M., Dawoud, S.M., and Kdair, M., "Optimal Placement and Capacity of Capacitor Bank in Radial Distribution System", International Conference on Energy Efficient Technologies for Sustainability, pp. 416-423, Iraq, 2016.

[23] Liu, C.C., Lee, S.J., and Vu, K., "Loss Minimization of Distribution Feeders: Optimality and Algorithms", IEEE Power Engineering Review, Volume 4, No. 2, pp. 1281-1289, Canada, 1989.
[24] IEEE Standard Board, "IEEE Recommended Practice for Electrical Power Distribution for Industrial Plants", The Institute of Electrical and Electronics Engineers, Inc, 345 East $47^{\text {th }}$ Street, pp. 488, USA, 1991.

[25] Rao, P.S.N., Deekshit, R., "Energy Loss Estimation in Distribution Feeders", IEEE Transactions on Power Delivery, Volume 21, No. 3, pp. 1092-1100, India, 2006. 